\title{
Supply Chain Quality Management Practices, Complementary Firm Assets, Competitive Advantage and Firm Performance
}

\author{
Ondiek Tobias Okoth ${ }^{1, *}$, Odock Stephen Ochieng(PhD $)^{2}$ \\ ${ }^{I}$ PhD Candidate, Department of Management Science, School of Business, University of Nairobi \\ ${ }^{2}$ Lecturer, Department of Management Science, School of Business, University of Nairobi
}

*Corresponding Author: Ondiek Tobias Okoth, PhD Candidate, Department of Management Science, School of Business, University of Nairobi, Kenya

\begin{abstract}
The literature review was intended to examine the nature of relationship that exists between supply chain quality management (SCQM) practices, complementary firm assets, competitive advantage and organizational performance. This was necessitated by the need to identify the SCQM practices, complementary firm assets, indicators of competitive advantage and multiple dimensions of firm performance for the purpose of developing a conceptual model. The study discussed relevant theories on which relationships between SCQM practices, firm characteristics, competitive advantage and organizational performance are anchored. Next relationship between the variables is highlighted. A summary of previous studies was then presented emphasizing the authors, key objectives, findings, knowledge gaps and how this study will address the gaps. The section ends with formulating hypotheses based on the developed conceptual framework. The comprehensive model will available to researchers for testing, review and modification in various contexts and managers as performance and supply chain evaluation and auditing. The study found that variables are multidimensional and developed a conceptual framework. However, the model should be subjected to empirical testing.
\end{abstract}

\section{INTRODUCTION}

Firms are under pressure to meet their internal and external obligations (Lin, Kuei \& Chai 2013). In the process, they must compete through networks and create systems that guarantee long term positive results for their survival (Quang, 2016).Pursuing quality management along supply chain referred to as supply chain quality management (SCQM) brings synergy which facilitates integration among network members (Fernandes, Sampaio \& Carvalho, 2014). Complementary firm assets (CFA) namely: leadership involvement, human resource management (HRM), trust among stakeholders, quality culture and established ICT facilitate SCQM practices implementation (Truong, Sampaio, Carvalho, Fernandes \& An, 2014). Performance is achieved when firms gain competitive advantage which is manifested in form of total cost reduction, timely deliveries, reduced lead times, increased productivity, improved quality of products, increased revenue and customer satisfaction (Chagooshi, Neshan \& Mogadam, 2015). The competitive advantage achieved leads to satisfaction of all stakeholders in multifaceted pattern (Forster 2008). Sustainable performance must encompass market share, financial rewards to investors, impact on society, the environmental impact, high level of firm integrity, operational efficiency or effectiveness, learning and growth (Kaplan \& Norton, 1996; Chagooshi et al., 2015; Ferreira, Silva \&Azevedo, 2016).

General systems theory supports the view that a firm's performance is amplified when components of the systems work together (Skytter, 2006). Various parties are involved in supply networks with heterogeneous demands whose satisfaction is anchored on stakeholder's theory. Relational view explains extension of competitive advantage from within firms to relationships among firms as a result SCQM adoption (Dyer \& Singh, 1998). Firms survive by interacting with their surroundings for resources which can be acquired more economically if pursued jointly by network members as underpinned by resource dependence theory (Scott \& Davies, 2007). These theories explain the relationship between SCQM, FCA, competitive advantage and organizational performance. 


\subsection{Supply Chain Quality Management}

Studies have confirmed that synergy is driven by integrating SCM and QM to SCQM supersedes benefits of SCM or QM adopted separately in firm performance improvement and gaining competitive advantage (Kashawa \& Burman, 2010; Zhong, Ma, Tu\& Li, 2016). Authors have therefore made efforts to define resultant SCQM variously. Ross (1998) defined SCQM as a network characterized by contribution of all those involved in supply chain purposefully to improve on work habits, all processes, services, products and deliveries aimed at favorable productivity, competitiveness and customer satisfaction outcomes. According to Robins and Malhotra (2005), SCQM is the coordinated, integrated and optimized quality activities within the supply chain for effective management of product quality and processes to deliver better market share, competitive advantage and customer satisfaction. Forster (2008) contributed to this debate by describing SCQM as system crafted to join customers with their suppliers in a commercial setting for the purpose of improving performance results to all stakeholders.

The objectives of SCQM practices are to correctly meet market demands, improve operational performance, satisfy all stakeholders, and financially reward firms by facilitating quality activities, processes and communication among network members (Kuei et al., 2001). Notably, according to the authors there is no consensus on whether SCQM is a chain, a network or a system. The definitions retain quality guiding principles of continuous improvement, teamwork and customer satisfaction in the perspective of supply chain. In view of the above observations this study defines SCQM as systemic networks where quality management practices and managing supply chains are integrated to synergistically improve products, processes, resources and partnerships to equally reward stakeholders namely; investors, organizations, customers, community and environment.

\subsection{Complementary Firm Assets}

Firm complementary assets (CFA) are firm's support systems vital for successful implementation of SCQM that give the firms competitive advantage (Farnandes et al., 2017). CFAs are thus a key relational capital that links operations among supply networks partners (Zang \& Huo, 2013). Based on literature review these assets include; ICT, top leadership support, HRM, work culture and trust (Forster, 2008; Lin et al., 2013; Truong et al. 2014).

This study defines CFA as system components resident in firms that fortify SCQM execution for competitiveness and firm performance. The assets explain when and whom SCQM practices and performance relationship is stronger or positive. The study will henceforth adopt ICT, HRM, leadership support, trust and culture as CFAs based on literature reviewed (Vanichichai \& Igel, 2011; Zang \& Huo, 2013; Truong el al., 2014; Farnandes et al., 2017). This is a departure from the common operationalization of age, size, industry type, ownership and organizational structure in most past studies.

\subsection{Competitive Advantage}

Competitive advantage is the acquisition of a defendable superior market share or profitability above competitors as a product of effective cost management during operations and value addition to customers (Sigalas, 2015). According to the author, competitive advantage is generated when firms exploit niche market opportunities, mimic threats from competition, differentiate their products from competition and are innovative. The established or inherited flexibility, delivery dependability, reduced cost and innovation capabilities should be not inimitable by other firms (Chagooshi et al., 2015)

Organizations have resident unique possessions, competences, market positions or market obstacles that can influence its superior performance (product of competitive advantage) in an industry (Sigalas, 2015). Both Li et al. (2004) and Kashwaha and Burman (2010) operationalize competitive advantage in terms of cost of production or price paid for a product, quality of product, dependable deliveries, extent of innovation and time to market. The same variable can as well quantified on the basis of extent of total cost reduction, market opportunity exploitation and competitor threat neutralization 
(Sagalas, 2015). The suggested measures quantify operation and financial performance or capabilities that differentiate a firm from competitors.

\subsection{Organizational Performance}

Performance is evaluation of the extent to which a particular management choice of action achieves pre-established standard or goal (Handfield, Monczka, Guinipero\& Patterson, 2011). Private firms aim for high profits upon customer satisfaction while the public organizations pursue better service quality. Complex business networks are characterized by high uncertainty, ambiguity and conflicts necessitating a wider scope of performance measurement in order to survive (Geesrbro\& Ritter, 2010). Still, there is need to understand external and internal performance given the infinite composition of stakeholders with heterogeneous performance objectives. Continuous performance measurements play key role in business process especially in planning, decision making, motivation of employees and communication across networks (Bourne, Kennerly\& Santos, 2005).

Vidanje and Santes (2007) indicated that European Foundation for Quality Management (EFQM) can report people, customer, society and key performance dimension. Kaplan and Norton (1996) faulted adequacy of financial performance metric as short term, historical and convenient just for reporting to shareholders. He thus advocated for use of Balanced Score Card (BSC) as a more strategic performance measurement tool that cater for owners, organization and other external interested parties. Whereas EFQM excellence model is inclined towards diagnostic role and empiricism, BSC is more of a strategic tool and scientific. Concurrent use of the two is superior (Shulver, Lawrie, House \& Street, 2009). Chagooshi et al. (2015), preferred inclusion of corporate social responsibility, environmental safety, internal processes, external supply chain, market, finance, quality and environment. This study proposes hybrid performance measurement framework that includes EFQM, BSC and those suggested by Chagooshi et al. (2015).

\section{RESEARCH PROBLEM}

Researchers have reported positive financial and non-financial organizational outcomes across industries and continents due to SCQM adoption (Kuei \& Madu, 2001; Robinson \& Malhotra, 2005; Farnandes et al., 2017; Ramish \& Aslam 2016; Farnandes et al., 2017; Abdallah, Abdullah \& Saleh 2017). However, there is concern on whether competitive advantage will lead to improved performance as measured by financial, market share, societal impact, operations, learning and Growth, environmental impact, customer satisfaction (Chagooshi et al., 2015). To adequately understand the relationship between SCQM implementation and performance of hospitals in Kenya it is also essential to clarify the role played by CFAs and competitive advantage in the relationship (Vanichchinchai \& Igel, 2014)

Operations management scientists, quality experts and supply chain practitioners have directed momentous efforts to establish whether SCQM automatically leads to improved firm performance through several studies. Critical analysis of the available studies presents weighty gaps. Major concern as one navigates the literature is differential operationalization of SCQM practices and organizational performance. While some studies considered multidimensional coverage of some incoherent facets of SCQM and performance unlimited to nomenclature (Truong et al., 2014), other researchers opted for one dimensional analysis of the study variables (Kuei \& Madu 2001). Nosratpour et al. (2015) emphasized the synergy realized through interaction of the SCQM practices on improved firm performance. The contribution of individual components of study variables appears valuable in model generation and testing. The incomplete consideration of sub variables, lack of consensus on what constitutes SCQM, CFA, competitive advantage and organizational performance among researchers presents ambiguity, lack of comparison and generalization, hinders universalism and propagates contradictions of findings. To firmly resolve this dispute, this study will make attempt to consider all relevant facets SCQM, firm characteristics, competitive advantage and OP to boost common understanding (Norton, 1996; Vidanje \& Santes 2007; Quang, 2016).

Evidence of direct link between SCQM practices and organizational performance is available in literature (Ombwoyo \& Atambo, 2017; Truong, 2014; Quang, 2016). Apparently, Chaghooshi et al. 
(2015) found that SCQM practices lead to competitive advantage. Li et al (2004) showed that SCM practices secure competitive advantage for improved organizational performance. Vanichichinchai and Igel (2010) reported mediating role of SCM on the relationship between TQM and supply performance. Zhong et al. (2016) contended existence of mediation effect of SCQ on QM/SCM practices and hotel performance relationship. Mediation in SCQM practices and firm performance relationship presents entropy that need to be resolved. Even though Lin et al. (2013) hinted that certain organization characteristics facilitate SCQM practices implementation, the moderating role of CFAs in link between SCQM practices has not received sufficient attention. To bring out the relationship between SCQM and OP better, there is need to investigate moderation effect of all possible CFAs and mediation of competitive advantage in the relationship. This study intends to fill this gap by investigating moderation and mediation in the relationship.

Still, there exist notable variances in empirical methodology and analytical techniques adopted by researchers. The models are built from case studies (Vanichichinchai \& Igel, 2010), literature reviews (Kashwaha \& Barman, 2010; Truong, 2014; Farnandes et al., 2017), combination of literature review and empirical research (Chaghooshi et al., 2015; Quang et al., 2016). Various data analysis techniques have also been employed including correlations (Chaghooshi et al., 2015), SEM (Li eta al., 2004; Lee et al, 2011;Abdallah et al., 2017; Zhong et al., 2016), path analysis (Nosratpour\& Hamid, 2015), regression analysis (Sharma \& Modgil, 2015) and MANOVA (Vanichchinchai, 2014). This has produced mixed set of results. This study aims to review literature to identify an analytical tool that can simultaneously test the whole construct to avoid mixed results.

There is adequate evidence from the foregoing discussion that there is need for farther research to address the identified knowledge gaps. This particular study therefore seeks to address the gaps by providing answers to the following questions. What is the relationship between SCQM practices, complementary firm assets, competitive advantage and organizational performance?

\section{RESEARCH OBJECTIVES}

The main objective of the study is to establish the relationship between supply chain quality management practices and performance of hospitals in Kenya. The specific objectives will be to:

- Establish the relationship between SCQM practices and performance of private hospitals in Kenya.

- Determine the influence of CFAs on the relationship between SCQM practices and performance of hospitals in Kenya.

- Examine the influence of competitive advantage on the relationship between SCQM practices and performance of hospitals in Kenya.

- Find out the joint effect of SCQM practice, CFAs, competitive advantage on performance of private hospitals in Kenya.

\section{VALUE OF THE STUDY}

The study intends to redirect managers from traditional performance measurement techniques and internalized business operations to design and management of the entire supply chain with a strategic focus. This is anchored on the fact that both SCQM practices and suggested hybrid organizational performance system tend to have systemic long term implications on survival of firms and sustainable improvement on hospital performance in light of environmental changes that have taken place over the last three decades. The resultant model and the framework upon completion will contribute valuable information towards theoretical foundation of both SCQM and performance useful to researchers and scholars since it will facilitate deep understanding of the impact SCQM practices on performance of firms. The study is expected to provide a valuable guide for the implementation and measurement of SCQM practices and performance respectively among hospitals in Kenya where data is currently fragmented and scanty for gaining global competitive advantage, customer satisfaction and ultimate performance. Finally knowledge and information gathered will be useful in improving quality of health care services, patient clinical outcomes, reduce overall healthcare costs and expand 
healthcare services to a larger proportion of population important for economic growth and improved quality of life among Kenyans.

The study findings are important to the Governments through their agencies in formulating policies that can be adopted in the public health sector due to merits of adopting supply chain quality management practices in the hospitals. The findings of this research will assist the regulatory agencies to identify the areas where to allocate resources. Private hospitals will also get guidance on how to better their supply chain strategies and policies for improved performance. These will help streamline SCQM practices in hospital for a healthier nation. The study may also provide information which can draw government's attention and attract the concerned players to rethink and refocus on this neglected sector.

\section{LITERATURE REVIEW}

\subsection{Theoretical Foundation of the Study}

\subsubsection{General Systems Theory}

General systems theory (GST) emphasizes the extra benefits that accrue from interrelationships and interdependence of system objects and their characteristics (Skyttner, 2006). The author asserts that in any system every element modifies the entire system, interdependence exits among components, system components impact on the system and no subcategories of the portions formed independently impacts the whole system. SCQM, CFA, competitive advantage and performance relationship is fastened on system's characters of order, pattern and purpose with permanence of distinctiveness and objective directedness. SCQM practices facilitate inter and intra-firm interactions that ensure reversible seamless flow of materials, information and money for the benefit of all stakeholders with support of certain organizational conditions (Chang, 2009). The interconnected components therefore work in tandem to generate competitive advantage crucial for superior firm performance (Truong et al., 2014; Sharma \&Modgil, 2015).

GST is based on axioms that are realistically unfeasible to prove and remain judgmental. Conflicting demands by parties in supply systems subject them to turbulence as parties can provoke system change through addition, replacement or suppression of its components (Farnandes et al., 2017). Therefore achieving universality of firms' characteristics and purpose is elusive. Skyttner (2006) stated that GST prioritized for understanding the relationships among variables rather than establishing the relationships. He points out that qualitative and descriptive requirement restricts parameterizing, measurements and predictions. However, it addresses problems beyond typical reductionist limits. GST is purportedly abstract and general but can unveil relative matches between different systems and hierarchical levels. This study is anchored GST for its ability to deliver a transdisciplinary outline for concurrent critical and normative examination of the correlation between all system elements.

\subsubsection{Stakeholders Theory}

Stakeholder's theory posits that management decisions must target investors and interested parties in a business venture (Freeman, 2010). Adoption of SCQM practices caters for suppliers, customers, employees, stockholders, governments, competitors, consumer advocates, environmentalists, special interest groups and the media. As such SCQM as system should ensure employees work in a safe environment, the society reap from the organization's existence, customers get value for money and there is sufficient cash flow for investors (Laplum, Sonopar \& Litz, 2008). The stakeholder's theory approach fairly fits the firm in its environment. For example, in the past, global pharmaceutical firms have been forced by NGOs to drop the patents of ARVs to be affordable (Munilla\& Milles, 2005).

Critics of stakeholder theory contend that firms are forced to benefit stakeholder void of any substantial investment from them at the expense of profits to the investors (Laplum et al., 2008). Proponents of the theory argue that ethical misconduct, corporate negligence and negative impacts of organizations on the society are prevented. Additionally, stakeholders' theory minimizes conflict of interest between stakeholders and solves complex management problems simultaneously (Mainardes, Alves \& Raposo, 2011). Choi and Wang (2009) argued that stakeholder oriented firms induce 
customers to demand more of their products or pay premium prices, employees to work harder to enhance the firm's effectiveness, suppliers to be more willing to engage in knowledge sharing with the firm resulting competitive advantage. In pursuit of comprehensive performance, firms which adopt SCQM practices tend to uniquely address plight of significant stakeholders which bring good relationship to yield sustainable competitive advantage and improved performance.

\subsubsection{Relational View}

Relational view posits that inter-firm resources and procedures contribute to better performance and survival of firms (Dyer \& Singh, 1998). This shifts competitive advantage to relationships underpinned by assets unique to the relations, their effective management, knowledge sharing and complementary resources or capabilities. The extension enables firms to benefit from relational rents co-generated only in trade relationships. Relational view explains how SCQM practices integrate firms with their customers, suppliers and other stakeholders (Kaynak\& Hartley, 2008).Joint competitive advantage in terms of total operating cost reduction by firms in the relationship is synergistically created through specific inter firm rent and connectivity in the networks for the mutual economic benefits of the firms and to the benefit of other stakeholders (Levie, 2006).

Dyer and Singh (2008) contended that relational view is a more realistic pathway to explain competitive advantage and performance than resource based view. They cited accessibility of standard input at economic cost to all competing firm. It is therefore the uniqueness of combination of resources by trading firms that dictates level of competitive advantage for supernormal benefits. The relational view integrates RBV and network theory to clarify mechanisms used by firms to craft competitive advantage (Dyer \& Singh, 1998). Sousa and Castro (2015) on the contrary argued that some business relations are burdens or liabilities to firms. Even though the value of business relationships in improving performance is real, their permanence, relevance and stability need to be continually reevaluated. Relational view highlights mutual gains that joint cohorts fail to generate individually.

\subsubsection{Resource Dependence Theory}

Resource Dependence Theory contends that firms exploit SCQM practices to intermingle among themselves and the environment to control internal conditions or actions and acquire vital resources for survival ( $\mathrm{Li}$ et al., 2011; $\mathrm{Zu}$, Kaynak\& Hartley, 2012). SCQM practices facilitate the network members to economically gain access to environmental resources through resource sharing putting them at advantage above competing firms and chains. Network members as a unit therefore minimally rely on their environments for resources which are otherwise available at elevated costs. Control over vital resources reduces reliance and dependence on other firms (Barringer \& Harrison, 2000). Firms therefore pursue objectives jointly via activity coordination and knowledge or resources sharing strengthening the entire supply chain to symbiotically curtail possible conflicts (Barringer \& Harrison, 2000; Scott \& Davis 2007).

The fact that RDT excludes development of competence, transactional costs and learning opportunities limits its ability to explain fully supply chain collaboration. Instead, it mimics mergers, board interlocks, provides forum for inter organizational relationship interpretation and minimizes failure prompted by constraints localized through power based exchange (Pfeffer, 2005). SCQM practices constrain reliance of supply chain partners as a whole on their environments through resources sharing mechanism reducing the applicability of RDT. RDT ignores unbalanced power that may accrue among partners due to differential resource ownership which may generate conflicts. RDT merely argues for exchange between firms environments for resources since no firm is an island or self- reliant instead of candidly elucidating supply chain quality management. Barringer and Harrison (2000) fault RDT inability to account for costs of transaction, capability growth, and knowledge enhancement chances.

\subsection{SCQM and Organizational Performance}

SCQM practices ensure quality along the entire supply chain that amplify performance among firms in the network (Vanichchinchaia \& Igel, 2011; Quang et al., 2016; Zhong et al., 2016; Farnandes et al., 2017). The externalization of quality to customers and suppliers ensures that quality materials and product enter and exit the supply chain (Robinson \& Malhotra, 2005). SCQM practices provide an 
avenue for early engagement, collaboration and communication among the parties (Lin et al., 2013). These facilitate interaction among suppliers, firms and customers to craft, produce and deliver quality products to customer for both financial and non-financial gains to hospitals.

Integration of supply networks need information to eliminate unnecessary stock, poor customer management, revenue loss, primitive capacity planning, confusion in transportation and uneconomical production (Zhou et al., 2014). Postponement ensures flexible delivery volumes and schedules that minimize losses while optimizing operation processes that enhance performance (Madu \& Kuei 2004). Continuous process design, management and improvement ensure full customer satisfaction and increase value to all other stakeholders for excellent business results (Paghaleh, 2011). The study therefore proposes as follows: SCQM practices namely supplier quality management, customer focus, information sharing, postponement, continuous process improvement and coordination) positively impact on financial, societal, environmental, market, operational and leaning/growth organizational performance.

\subsubsection{SCQM, Complementary Firm Assets and Organizational Performance}

CFAs provide a strong base for implementation of SCQM practices (Lin et al., 2013). Top management support provides motivation and resources for effective implantation of customer focus, quality supplier management, process management and information sharing (Magretta, 2008). The leadership allocates sufficient resources to conduct research on customer expectations, source quality inputs, minimize complexity and variance in processes, eliminate wastes, damages, rework and share knowledge (Robonson \& Malhotra, 2005). Information and communication technology (ICT) integration support accurate data storage and exchange necessary for information sharing along the supply chain (Quang et al., 2016). This permits high quality data generation, reporting and information. Information sharing facilitates accurate decision making, quality dimensions awareness among stakeholders and early problem detection for timely remedy. Trust and transparency culture applied in supply chains minimizes conflicts and uncertainties in the supply network for improved performance (Truong et al., 2014).

SCQM implementation depends on level, use, storage and sharing of knowledge and skills of the employees (Azizi et al., 2016). Firm's knowledge on SCQM practices and its role in improving performance serves as a motivator for its adoption Information technology is vital for the integration, monitoring, analysis and enabling intra and inter firm processes (Fanandes et al., 2016). There is moderating effect of CFAs namely; HRM, leadership support, trust, ICT and culture on the relationship between SCQM and organizational performance by ensuring effective and sustained implementation of SCQM practices (Azizi et al., 2016; Gomez et al., 2015; Truong et al., 2014; Quei et al., 2013). The study proposes that CFAs significantly influence direction and strength of the relationship between SCQM practices and organizational performance.

\subsubsection{SCQM Practices, Competitive Advantage and Organizational Performance}

Firms that execute SCQM practices gain competitive advantage that explains their improved performance (Chagooshi et al., 2015; Li et al., 2006; Caden et al., 2013). They are able to reduce total cost, delivery uncertainties, inflexibilities as well as ensuring short time to market for improved firm performance (Sagalas, 2015). The competitive advantage among members in the same chain and integration of the processes leads to elevated multidimensional firm performance (Lin et al., 2014). Firms drive performance from synergistic effect of SCQM practices that allow them to reliably deliver quality products to end customers at minimum price and time (Quang et al., 2016). Customer value created, cost reduction and better products differentiate the firm and grant them competitive advantage (Chagooshi et al., 2015).

Information sharing leads to total cost reduction, increased order fulfillment rate and reduced cycle time. It integrates partners to secure dependable delivery and acceleration of time to market that leaves customer satisfaction exceeded (Truong et al., 2014). Supplier quality management and postponement contribute to reduced cost/ price, time to market, increased customer responsiveness flexibility and efficiency. Li et al. (2004) found a relationship between SCM and competitive advantage. Chagooshi et al. (2016) established a positive relationship between SCQM and 
competitive advantage. The study proposes that SCQM practices create a competitive advantage which mediates the relationship between SCQM practices for financial and non-financial performance of firms.

\subsubsection{SCQM Practices, CFAs, Competitive Advantage and Performance}

FCAs enhance SCQM practices adoption giving the firms in the network competitive advantage leading to improved performance (Gomez et al., 2015; Quang et al., 2016; Zhong et al., 2016; Kuei et al., 2010). The elements of SCQM, CFAs and CA interact systematically to deliver better results than when pursued in isolation by firms (Kuei \& Madu 2001). The competitive advantage achieved by firms due to SCQM practices implementation leads customer satisfaction that motivates payment of premium prices to maximize profits (Lin et al., 2014). There is also evidence of interaction among elements constituting individual latent variables and among constituents of different constructs.

Trust between firms and shared quality culture catalyzes supplier integration and this leads to timely deliveries which is competitive advantage and improved operational performance (Abdallah et al., 2017). Employees with skills and knowledge have ability to analyze data extract information regarding desired quality products or competitive advantage to deliver customer satisfaction (Ramish \& Aslam, 2016). Effective SCQM practices implementation facilitated by relevant organizational factors creates competitive advantages that guarantee firms sustainable organizational performance improvement (Farnandes et al., 2016; Abdullah et al., 2017). This study proposes that there is joint effect of SCQM practices, organizational factors and competitive advantage on firm performance which is greater than the sum total of the contributions of the individual variables on organizational performance.

\subsubsection{Summary of Knowledge Gaps}

Objective of the tabulated information is to highlight studies that have been conducted on SCQM, competitive advantage, firm characteristics and organizational performance in terms of study focus, methodology, findings and knowledge gaps and how this study will addresses the gaps.

Table2.1. Summary of Knowledge Gaps

\begin{tabular}{|c|c|c|c|c|c|}
\hline Author & Study Focus & Methodology & Findings & Gap in Knowledge & $\begin{array}{c}\text { How the study } \\
\text { addresses the gap }\end{array}$ \\
\hline $\begin{array}{l}\text { Vanichichinchai } \\
\text { \& Igel (2010) }\end{array}$ & $\begin{array}{l}\text { Assessed } \\
\text { relationship btw } \\
\text { TQM, SCM and } \\
\text { supply } \\
\text { performance. }\end{array}$ & $\begin{array}{l}\text { Case study of two } \\
\text { Thailand auto- } \\
\text { mobile firms. } \\
\text { Used SEM and } \\
\text { Path analysis. }\end{array}$ & $\begin{array}{l}\text { SCM mediates positive } \\
\text { relationship between } \\
\text { TQM and supply } \\
\text { performance }\end{array}$ & $\begin{array}{l}\text { SCQM not used as } \\
\text { independent variable. } \\
\text { Role of FCAs and } \\
\text { competitive advantage } \\
\text { in the SCQM- } \\
\text { performance relation- } \\
\text { ship not established. }\end{array}$ & $\begin{array}{l}\text { SCQM to be used } \\
\text { as independent } \\
\text { variable. Determine } \\
\text { role of competitive } \\
\text { advantage and } \\
\text { FCAs in the } \\
\text { relationships }\end{array}$ \\
\hline 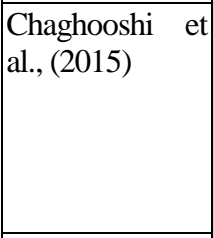 & $\begin{array}{l}\text { Assess the } \\
\text { relationship } \\
\text { between SCQM } \\
\text { and competitive } \\
\text { advantage }\end{array}$ & $\begin{array}{l}\text { Used conical } \\
\text { correlation to } \\
\text { analyze data }\end{array}$ & $\begin{array}{l}\text { SCQM positively impacts } \\
\text { on firm's' competitive } \\
\text { advantage. Customer } \\
\text { focus and quality play } \\
\text { most critical role in the } \\
\text { relationship. }\end{array}$ & $\begin{array}{l}\text { Both performance and } \\
\text { CFAs variables not } \\
\text { addressed. }\end{array}$ & $\begin{array}{l}\text { Include variables } \\
\text { performance and } \\
\text { CFAs, }\end{array}$ \\
\hline $\begin{array}{l}\text { Nosratpour\& } \\
\text { Hamid (2015) }\end{array}$ & $\begin{array}{l}\text { SCQM practices } \\
\text { and performance }\end{array}$ & $\begin{array}{|lr|}\text { Cross } & \text { sectional } \\
\text { survey } & \text { Structural } \\
\text { equation } & \text { modeling }\end{array}$ & $\begin{array}{l}\text { SCQM practices impacts } \\
\text { organizational perfor- } \\
\text { mance positively. }\end{array}$ & $\begin{array}{l}\text { Findings relate to } \\
\text { automobile industry. } \\
\text { Dimensions of perfor- } \\
\text { mance not differen- } \\
\text { tiated }\end{array}$ & $\begin{array}{l}\text { Investigate more } \\
\text { dimensions of } \\
\text { variables. }\end{array}$ \\
\hline Quang (2016) & $\begin{array}{l}\text { Firm characteri- } \\
\text { stic, SCQM and } \\
\text { performance }\end{array}$ & Literature & $\begin{array}{l}\text { FCAs moderate SCQM } \\
\text { and performance } \\
\text { relationship. }\end{array}$ & $\begin{array}{l}\text { No } \\
\text { evidence }\end{array}$ & $\begin{array}{l}\text { Add competitive } \\
\text { advantage as } \\
\text { intervening } \\
\text { variable } \\
\end{array}$ \\
\hline \begin{tabular}{|l}
$\begin{array}{l}\text { Abdallah et al } \\
(2017)\end{array}$ \\
\end{tabular} & \begin{tabular}{|l|} 
Trust, supplier \\
integration and \\
performance
\end{tabular} & $\begin{array}{l}\text { Survey of private } \\
\text { hospitals in } \\
\text { Jordan, SEM }\end{array}$ & 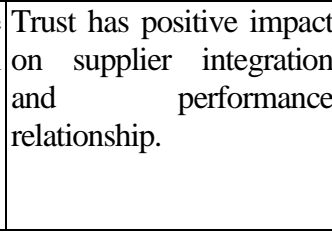 & $\begin{array}{l}\text { Relationship between } \\
\text { SCQM and OP not } \\
\text { investigated. }\end{array}$ & $\begin{array}{l}\text { Determine the joint } \\
\text { effect of SCQM, } \\
\text { CFAs and } \\
\text { competitive } \\
\text { advantage on } \\
\text { performance } \\
\end{array}$ \\
\hline
\end{tabular}




\subsubsection{Conceptual Framework}

Figure1 illustrates that SCQM practices entail supplier relationship management, customer focus, information sharing, postponement, Process management, coordination. Complementary firm assets are viewed in the lenses of leadership support, HRM, ICT, trust and culture. Competitive advantage can be measured using cost, delivery dependability, differentiation, time/ speed. Financial results, market share, societal impact, operational, environmental impact, customer satisfaction, learning and growth constitute organizational performance. $\mathrm{H}_{1}-\mathrm{H}_{4}$ hypothesized relationships between variables based on the theories and findings from literature review. The hypotheses are:

$\mathbf{H}_{\mathbf{1}}$ : There is a significant direct relationship between SCQM practices and organizational performance

$\mathbf{H}_{2}$ : Complementary firm assets have significant moderating effect on the relationship between SCQM practices and organizational performance

$\mathbf{H}_{3}$ : Competitive advantage significantly mediates the relationship between SCQM practices and organizational performance.

$\mathbf{H}_{4}$ : The joint effect of SCQM practices, CFAs and competitive advantage is greater than the sum total of the individual variables on organizational performance.

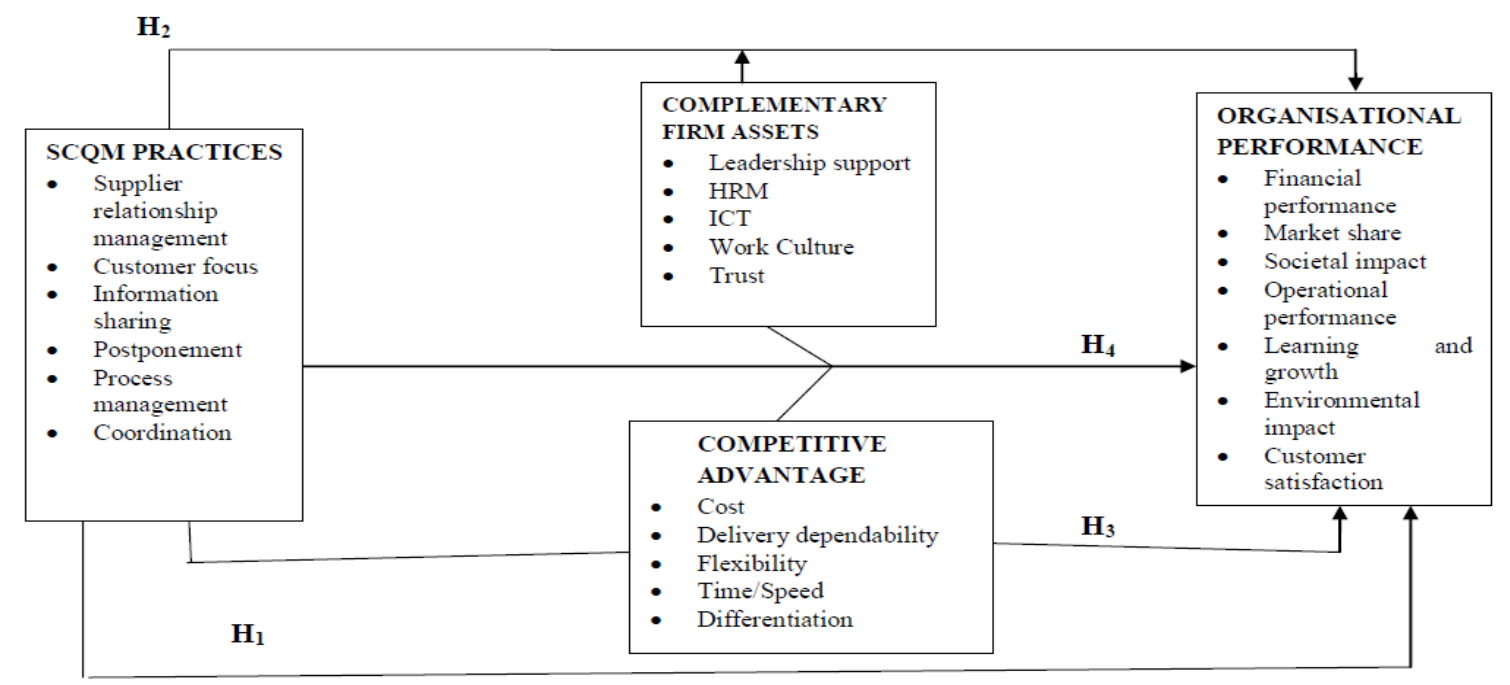

Figure1. Conceptual Framework

Source: Researcher, (2018)

\section{CONCLUSION}

Relevant theories predicting the nature of relationships among variables were identified. The found the relationship between the variables of the study specifically highlighted the links between SCQM and performance, SCQM, CFAs and performance, SCQM, competitive advantage and performance and SCQM, firm characteristics, competitive advantage and performance. A summary of related studies was then presented highlighting the authors, key objectives, findings, knowledge gaps and suggested how the gaps can be addressed. The study was concluded by formulating hypotheses based on the developed conceptual framework.

\section{REFERENCES}

[1] Abdallah, A. B., Abdallah, A. B., Abdullah, M. I., Abdullah, M. I., Mahmoud Saleh, F. I., \& Mahmoud Saleh, F. I. (2017). The effect of trust with suppliers on hospital supply chain performance: The mediating role of supplier integration. Benchmarking: An International Journal, 24(3), 694-715

[2] Asamoah, D., Abor, P., \&Opare, M. (2011).An examination of pharmaceutical supply chain for artemisini $\mathrm{n}$-based combination therapies in Ghana. Management Research Review, 34(7), 790-809.

[3] Athreya, K. B., \&Lahiri, S. N. (2006). Measure theory and probability theory. Springer Science \& Business Media.

[4] Awuor, O.E., \&Kinuthia, D.M.W (2013).Total Quality Management Practices in Selected Private Hospitals in Nairobi, Kenya. European Journal of Business and Management.5(13),32-44 
[5] Bhakoo, V., \& Chan, C. (2011). Collaborative implementation of e-business processes within the healthcare supply chain: the Monash Pharmacy Project. Supply Chain Management: An International Journal, 16(3), 184-193.

[6] Byrne, B. M. (2010). Structural equation modeling with AMOS: Basic concepts, applications, and programming (2nd. Edition) New York: Routledge.

[7] Carlos Bou-Llusar, Ana B. Escrig-Tena, Vicente Roca-Puig, InmaculadaBeltrán-Martín, (2005). To what extent do enablers explain results in the EFQM excellence model: An empirical study. International Journal of Quality \& Reliability Management, 22 (4), 337-353,

[8] Chaghooshi, A. J., Soltani-Neshan, M., \&Moradi-Moghadam, M. (2015). Canonical Correlation Analysis Between Supply Chain Quality Management And Competitive Advantages. Foundations of Management, 7(1), 83-92.

[9] Chang, G. (2009). Total quality management in supply chain. International Business Research, 2(2), 82.Carlos Bou-Llusar, Ana B. Escrig-Tena, Vicente Roca-Puig, InmaculadaBeltrán-Martín, (2005). To what extent do enablers explain results in the EFQM excellence model: An empirical study International Journal of Quality \& Reliability Management, 22 (4), 337-353.

[10] Dess, G. G., \& Robinson, R. B. (1984).Measuring organizational performance in the absence of objective measures: the case of the privately-held firm and conglomerate business unit. Strategic management journal, 5(3), 265-273

[11] Dyer, J. H., \& Singh, H. (1998). The relational view: cooperative strategy and sources of Interorganizational competitive advantage. Academy of Management Review, 23(4), 660-679.

[12] Fernandes, A. C., Sampaio, P., \&Carvalho, M. S. (2014). Quality management and supply chain management integration: a conceptual model. IEOM, 773-780.

[13] Ferreira, L. M. D., Silva, C., \&Azevedo, S. G. (2016).An environmental balanced scorecard for supply chain performance measurement (Env_BSC_4_SCPM). Benchmarking: An International Journal, 23(6), 1398-1422.

[14] Fish, L. A. (2011). Supply Chain Quality Management. Supply Chain Management-Pathways for Research and Practice, 25.

[15] Foster, S. T. (2008). Towards an understanding of supply chain quality management. Journal of Operations Management, 26(4), 461-467.

[16] Freeman, R. E. (2010). Strategic management: A stakeholder approach. Cambridge University Press..

[17] Granovetter, M. (1983). The strength of weak ties: A network theory revisited. Sociological theory, 201-233.

[18] Gómez-Cedeño, M., Castán-Farrero, J. M., Guitart-Tarrés, L., \&Matute-Vallejo, J. (2015).Impact of human resources on supply chain management and performance. Industrial Management \& Data Systems, 115(1), 129-157.

[19] Haque, M., \& Islam, R. (2013). Effects of supply chain management practices on customer satisfaction: Evidence from pharmaceutical industry of Bangladesh. Global Business and Management Research, 5(2/3), 120.

[20] Hill, C. W., \& Jones, T. M. (1992).Stakeholder-agency theory. Journal of management studies, 29(2), 131154.

[21] Kaplan, R. S., \& Norton, D. P. (1996).Using the balanced scorecard as a strategic management system.

[22] Kushwaha, G. S., \& Barman, D. (2010).Development of a theoretical framework of supply chain quality management. Serbian Journal of Management, 5(1), 127-142.

[23] Laplume, A. O., Sonpar, K., \&Litz, R. A. (2008). Stakeholder theory: Reviewing a theory that moves us. Journal of management, 34(6), 1152-1189.

[24] Law, K. M. (2016). How schedule issues affect drug logistics operations: an empirical study in hospitals in China. Industrial Management \& Data Systems, 116(3), 369-387.

[25] Lee, S. M., Lee, D., \&Schniederjans, M. J. (2011). Supply chain innovation and organizational performance in the healthcare industry. International Journal of Operations \& Production Management, 31(11), 1193-1214.

[26] Li, S., Ragu-Nathan, B., Ragu-Nathan, T.S., Rao, S.S. (2004). The impact of supply chain management practices on competitive advantage and organizational performance. OMEGA, 34 (2),107-124.

[27] Liapis, N., Theodorou, D., \&Zannikos, F. (2013). Absence of TQM across the fuel supply chain: quality failure-associated costs. Total Quality Management \& Business Excellence, 24(3-4), 452-461.

[28] Lin, C., Kuei, C. H., \& Chai, K. W. (2013). Identifying critical enablers and pathways to high performance supply chain quality management. International Journal of Operations \& Production Management, 33(3), 347-370. 
[29] Maiga, A. S. (2015). Organizational Learning and Firm Profitability: The Role of Competitive Advantage. In Advances in Accounting Behavioral Research (pp. 179-211). Emerald Group Publishing Limited.

[30] Nosratpour, M., \& Hamid, A. B. A (2015) The Impact of SCQM Practices on Organizational Performance.

[31] Quang, T.H, Sampaio, P, Carvalho, M.S Ana Cristina Fernandes, A.C, An D.T.B, Vilhenac, E (2016). An extensive structural model of supply chain quality management and firm performance International Journal of Quality \& Reliability Management, 33(4), 444-464.

[32] Robinson, C. J., \&Malhotra, M. K. (2005).Defining the concept of supply chain quality management and its relevance to academic and industrial practice. International Journal of Production Economics, 96(3), 315-337.

[33] Ross, D. F. (1998), Competing Through Supply Chain Management, New York, Chapman \& Hall.

[34] Scott, W. R., \& Davis, G. F. (2007). Organizations and organizing: Rational, natural, and open system perspectives. Upper Saddle River, NJ: Pearson Prentice Hall.

[35] Sigalas, C. (2015). Competitive advantage: the known unknown concept. Management Decision, 53(9), 2004-2016.

[36] Sharma, S., \&Modgil, S. (2015). Supply chain and total quality management framework design for business performance-case study evidence. Journal of Enterprise Information Management, 28(6), 905930.

[37] Skyttner, L. (1996). General systems theory: origin and hallmarks. Kybernetes, 25(6), 16-22.

[38] Truong, H., Sampaio, P., Carvalho, M. S., Fernandes, A. C., \&An, D. T. B. (2014). An extensive structural model for supply chain quality management and firm performance. In ICQEM Proceedings of the 1 st International Conference on Quality Engineering and Management, 2014 (pp. 115-131).ICQEM.

[39] Vanichchinchai, A., \&Igel, B. (2011).The impact of total quality management on supply chain management and firm's supply performance. International Journal of Production Research, 49(11), 3405342.

[40] Zhong, J., Ma, Y., Tu, Y., \& Li, X. (2016). Supply chain quality management: an empirical study. International Journal of Contemporary Hospitality Management, 28(11).

[41] Zhao, J., Hu, Y., \& Wang, Y. (2015). Supply chain quality management based on information asymmetry. International Journal of Sociology Study.

[42] Zikmund, W.G. (2003) Business Research Methods. 7th Edition, Thomson South Western, Ohio

\section{AUTHOR'S BIOGRAPHY:}

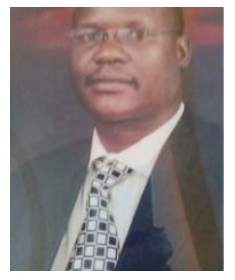

Ondiek Tobias Okoth, holds Bachelor of science in Biochemistry and Zoology (Kenyatta University), Masters of Business Administration (University of Nairobi) and currently Ph.D candidate, Department of management Science (Operations Management option), School of business University of Nairobi, Kenya

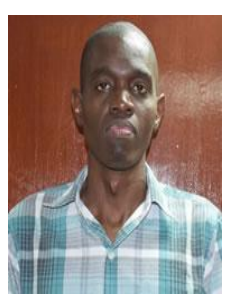

Odock Stephen Ochieng, PhD, Is a Lecturer Department of Management Science, in the School of Business, University of Nairobi, Kenya.

Citation: Ondiek Tobias Okoth, Odock Stephen Ochieng(PhD). "Supply Chain Quality Management Practices, Complementary Firm Assets, Competitive Advantage and Firm Performance" International Journal of Managerial Studies and Research (IJMSR), vol 6, no. 2, 2018, pp. 18-28. doi:http://dx.doi.org/10.20431/ 2349-0349.0602003.

Copyright: (c) 2018 Authors. This is an open-access article distributed under the terms of the Creative Commons Attribution License, which permits unrestricted use, distribution, and reproduction in any medium, provided the original author and source are credited. 